\title{
Atypical ultrasound features of parathyroid tumours may bear a relationship to their clinical and biochemical presentation
}

\author{
Anuradha Chandramohan • Kirthi Sathyakumar • Reetu Amrita John • \\ Marie Therese Manipadam • Deepak Abraham • Thomas V. Paul • Nihal Thomas • \\ M. J. Paul
}

Received: 10 August 2013 /Revised: 4 October 2013 / Accepted: 21 October 2013 / Published online: 29 November 2013

(C) The Author(s) 2013. This article is published with open access at Springerlink.com

\begin{abstract}
Objectives To describe atypical ultrasound features of parathyroid lesions and correlate them with clinical presentation and histopathology.

Materials and methods Retrospective review of 264 patients with primary hyperparathyroidism who underwent ultrasound
\end{abstract}

A. Chandramohan · K. Sathyakumar · R. A. John

Department of Radiology, Christian Medical College, Vellore, Tamil

Nadu, India 632004

K. Sathyakumar

e-mail: kirthi86s@yahoo.com

R. A. John

e-mail: johnreetu@yahoo.com

M. T. Manipadam

Department of Pathology, Christian Medical College, Vellore, Tamil

Nadu, India 632004

e-mail:mtm2005@cmcvellore.ac.in

D. Abraham • M. J. Paul

Department of Endocrine surgery, Christian Medical College,

Vellore, Tamil Nadu, India 632004

D. Abraham

e-mail: abrahamdt@gmail.com

M. J. Paul

e-mail: mjpaul@cmcvellore.ac.in

T. V. Paul $\cdot$ N. Thomas

Department of Endocrinology, Christian Medical College, Vellore,

Tamil Nadu, India 632004

T. V. Paul

e-mail: thomasvpaul@yahoo.com

N. Thomas

e-mail: nihal_thomas@yahoo.com

A. Chandramohan $(\bowtie)$

Department of Radiology, Christian Medical College, Vellore, Tamil

Nadu 632002, India

e-mail: anuradhachandramohan@gmail.com imaging prior to parathyroidectomy was performed. Patients with atypical ultrasound findings $(n=26)$ were identified; imaging findings were correlated with clinical presentation and histopathology.

Results Twenty-one (80 \%) lesions were adenomas, two (8\%) were adenomas with cellular atypia, and three (11.5\%) were carcinomas. Seventeen (65\%) lesions showed cystic change; five $(19 \%)$ of them had $>50 \%$ cystic change. These lesions were adenomas with cystic degeneration. Cystic degeneration had significant positive correlation with the lesion size and PTH level, but cystic adenomas correlated negatively with lesion weight. Six (23\%) lesions were isoechoic and one (4\%) was hyperechoic; histology predominantly revealed haemorrhage, hyalinisation and fibrosis; one lesion showed fat deposition and another had multiple granulomas within the adenoma. Twenty (83 \%) lesions had heterogeneous echotexture and showed combinations of acinar dilatation, necrosis, haemorrhage and fibrosis. Heterogeneous lesions tended to be significantly larger and heavier, and they were associated with higher PTH levels. Four (15\%) lesions had calcifications. Scintigraphy was concordant in $22(96 \%), n=23$. One scintigraphy-negative lesion was a cystic parathyroid adenoma.

Conclusion Atypical ultrasound features of parathyroid lesions pose a diagnostic challenge. Awareness of these features would help improve lesion detection.

Teaching points

1.Cystic change is significantly related to the size, weight and measured parathyroid hormone levels.

2. Cystic change in parathyroid tumours indicated a slightly higher risk of malignancy.

3.Heterogeneous parathyroid adenomas are larger in size and heavier, and they have higher PTH levels.

4. Awareness of atypical ultrasound features will improve preoperative clinical prediction. 
Keywords Atypical features · Parathyroid · Ultrasound · Histopathology

\section{Introduction}

Primary hyperparathyroidism is a common endocrine disorder that can result from adenoma or hyperplasia of the parathyroid gland. In $80-90 \%$ of cases it occurs as a result of benign adenoma of the parathyroid gland [1]. Sonography and Tc$99 \mathrm{~m}$ sestamibi scintigraphy are the imaging modalities of choice in arriving at a diagnosis [2, 3]. Surgical management is most common and provides symptomatic cure as well as biochemical normalisation.

Ultrasonography is a convenient and inexpensive imaging modality in the evaluation of the thyroid and parathyroid glands with a sensitivity and specificity of $98 \%$ and $88 \%$ [4]. The grey scale appearances and Doppler features favouring a diagnosis of parathyroid adenoma are well described. The classical imaging features on grey scale include oval or lobulated extra-thyroidal hypoechoic lesions with a well-defined margin. On colour Doppler these lesions are very vascular and typically show a peripheral vascular arc and prominent polar feeding vessel arising from the branches of inferior thyroidal artery. Other features include vascular asymmetry of the thyroid gland on the side of the lesion and hyperechoic capsule [3-5].

However, there is little literature on atypical ultrasound features of parathyroid lesions, their prevalence and relevance while evaluating parathyroid lesions. The atypical features so far described in the literature include purely cystic parathyroid adenomas [6] reported in $4 \%$ of all adenomas [7], cystic degeneration in solid adenomas, giant adenomas, inhomogeneous, multi-lobulated and calcified parathyroid tumours $[7,8]$.

The purpose of this study was to describe the atypical ultrasound features of parathyroid lesions, to study how they correlate with Tc-99m sestamibi scintigraphy and histopathology and clinical parameters.

\section{Materials and methods}

This retrospective study was conducted by the departments of radiology, pathology, and endocrinology and endocrine surgery of a 2,800-bed tertiary care teaching hospital in India on patients with parathyroid ultrasound showing atypical findings. Informed consent was waived with IRB approval. A comprehensive list of all patients who underwent surgery for primary hyperparathyroidism between the year 2000 to September 2012 was obtained from the Department of Endocrine Surgery database. Ultrasound images and reports of all the patients were reviewed from PACS (picture archiving and communication system) by three radiologists. Images were interpreted by predetermined criteria. Patients with classical ultrasound features such as hypoechoic, well-defined, solid lesion with homogeneous echotexture, a thin echogenic rim and polar extra-thyroidal feeding artery were excluded. Those patients with negative parathyroid ultrasonography were also excluded. Iso- or hyperechogenicity, heterogeneous echotexture with cystic change, purely cystic lesions and presence of calcification were considered atypical findings on parathyroid ultrasound. Criteria for cystic adenoma included a predominantly anechoic lesion with posterior acoustic enhancement. Cystic degeneration was described when there was a solid lesion with one or more anechoic areas within. Degree of cystic change was assessed on ultrasound images. An inhomogeneous echotexture was defined by the presence of hypoechoic areas mixed with areas of hyperechogenicity. Laboratory results such as pre- and postoperative serum calcium and parathyroid hormone levels, Tc-99m sestamibi scintigraphy, intraoperative findings and histopathology reports of these patients were reviewed from the clinical workstation.

\section{Statistical analysis}

Statistical analysis was done using IBM SPSS Analytics 16.0 software (Chicago, Ill., USA). To assess factors associated with atypical ultrasound findings, Fisher's exact test and chisquared test were performed to analyse categorical data; independent sample T-test was performed to analyse continuous data. Bivariate correlation analysis was performed to correlate the atypical ultrasound finding with biochemical and clinical

Table 1 List of ultrasound equipment and the frequencies of the highresolution probes used for parathyroid ultrasound examinations in our centre

\begin{tabular}{lll}
\hline Model, manufacturer & $\begin{array}{l}\text { Frequency range } \\
\text { of high-frequency } \\
\text { probes (MHz) }\end{array}$ & $\begin{array}{l}\text { Colour } \\
\text { Doppler }\end{array}$ \\
\hline ACUSON S2000 & \\
Xario XG, Siemens & $5-14,6-9$ & Yes \\
HD 11, Philips & $7-14$ & Yes \\
XARIO-ISTYLE, Toshiba & $3-12$ & Yes \\
ACUSON Antares ${ }^{\mathrm{TM}}$, Siemens & $7-14$ & Yes \\
LOGIQ 5 EXPERT, GE Health Care & $5-13,3-7$ & Yes \\
Ultramark 9 (UM9), ALT & $5-12$ & Yes \\
LOGIQ 500 PRO, GE Health Care & $7-12$ & Yes \\
LOGIQ 400 PRO, GE Health Care & $7-12$ & Yes \\
LOGIQ P6 BT, GE Health Care & $7-12$ & No \\
LOGIQ P6 BT PRO, GE Health Care & $7-12$ & Yes \\
SONOLINE G50 & Yes \\
SONOLINE G40mens & $5-10$ & Yes \\
\hline
\end{tabular}


Table 2 Characteristics of patients with parathyroid lesions with atypical ultrasound features

\begin{tabular}{|c|c|c|c|c|c|c|}
\hline $\begin{array}{l}\text { Patient } \\
\text { no. }\end{array}$ & Age & Sex & $\begin{array}{l}\text { Corrected } \\
\text { calcium } \\
(\mathrm{mg} / \mathrm{dl})\end{array}$ & $\begin{array}{l}\text { PTH } \\
(\mathrm{pg} / \mathrm{ml})\end{array}$ & $\begin{array}{l}\text { Size of } \\
\text { the lesion } \\
(\mathrm{mm})\end{array}$ & Histopathology \\
\hline 1 & 51 & M & 14.14 & 783 & $45 \times 25$ & Adenoma \\
\hline 2 & 48 & $\mathrm{~F}$ & 11.48 & 335.5 & $18 \times 8$ & Adenoma \\
\hline 3 & 61 & M & 12.46 & 677 & $40 \times 30$ & Adenoma \\
\hline 4 & 27 & M & 12.24 & 1,900 & $50 \times 40$ & Adenoma \\
\hline 5 & 62 & $\mathrm{~F}$ & 12.42 & 670 & $27 \times 20$ & Adenoma \\
\hline 6 & 48 & M & 14.16 & NA & $28 \times 17$ & Carcinoma \\
\hline 7 & 60 & $\mathrm{~F}$ & 12.62 & 1,692 & $45 \times 22$ & Adenoma \\
\hline 8 & 57 & $\mathrm{~F}$ & 11.94 & 2,500 & $35 \times 25$ & Adenoma \\
\hline 9 & 55 & M & 9.78 & 361 & $22 \times 14$ & Adenoma \\
\hline 10 & 41 & $\mathrm{M}$ & 14.66 & 2,056 & $29 \times 20$ & Carcinoma \\
\hline 11 & 66 & M & 10.6 & 765 & $10 \times 6$ & Adenoma \\
\hline 12 & 21 & $\mathrm{~F}$ & 12.26 & 2,500 & $27 \times 18$ & Adenoma \\
\hline 13 & 37 & $\mathrm{~F}$ & 11.74 & 2,500 & $60 \times 45$ & Adenoma \\
\hline 14 & 35 & $\mathrm{~F}$ & 12.3 & 1,082 & $40 \times 30$ & Adenoma \\
\hline 15 & 53 & $\mathrm{~F}$ & 11.84 & 491.7 & $35 \times 30$ & Adenoma \\
\hline 16 & 51 & $\mathrm{~F}$ & 11.84 & 206 & $32 \times 14$ & Adenoma \\
\hline 17 & 50 & $\mathrm{~F}$ & 10.14 & 410 & $43 \times 15$ & Adenoma \\
\hline 18 & 48 & M & 12.36 & 721.8 & $40 \times 30$ & Adenoma \\
\hline 19 & 44 & $\mathrm{~F}$ & 10.04 & NA & $25 \times 17$ & Carcinoma \\
\hline 20 & 49 & $\mathrm{~F}$ & 10.36 & 978 & $50 \times 50$ & Adenoma \\
\hline 21 & 58 & M & 12.46 & 1,132 & $30 \times 25$ & Adenoma \\
\hline 22 & 64 & $\mathrm{~F}$ & 11.28 & 190.7 & $15 \times 10$ & Adenoma \\
\hline 23 & 56 & $\mathrm{~F}$ & 12.42 & 1,062 & $30 \times 20$ & Adenoma \\
\hline 24 & 30 & $\mathrm{~F}$ & 12.08 & 1,900 & $\begin{array}{l}23 \times 19 \\
10 \times 4\end{array}$ & Double adenoma \\
\hline 25 & 43 & M & 11.46 & 1,104 & $32 \times 19$ & Adenoma \\
\hline
\end{tabular}

parameters, pathology and Tc-99m sestamibi scintigraphy findings. A p-value of less than 0.05 was considered as statistically significant.

\section{Results}

Patient characteristics

Out of 296 patients who underwent parathyroidectomy for primary hyperparathyroidism at our institution between 2000 and September 2012, 264 patients had ultrasound for preoperative localisation of abnormal parathyroid glands. A total of 25 patients [10 male and 15 female patients; mean age, 47.8 (range, 21-66) years] had 26 parathyroid lesions with atypical findings on ultrasonography. Mean $( \pm$ SD) of duration of illness in these patients was $40.3 \pm 65.2$ months (range, 1 month to 22 years). Mean $( \pm \mathrm{SD})$ of the serum calcium level just prior to surgery was $12.3 \pm 1.02 \mathrm{mg} / \mathrm{dl}$ (range, 10.1$14.5 \mathrm{mg} / \mathrm{dl}, \mathrm{n}=25)$; laboratory reference range, $8.3-10.4 \mathrm{mg} /$ dl. Mean $( \pm \mathrm{SD})$ of serum albumin was $4.3 \pm 0.6 \mathrm{~g} \%$ (range, 2.5-5.1 g \%); laboratory reference range, 3.5-5 g \%. Mean ( \pm $\mathrm{SD})$ of serum corrected calcium was $11.97 \pm 1.12 \mathrm{mg} / \mathrm{dl}$ (range, 9.8-14.7 mg/dl, $\mathrm{n}=25)$. Mean $( \pm \mathrm{SD})$ of the serum PTH level was $1,163.24 \pm 760.67 \mathrm{pg} / \mathrm{ml}$ (range, 191-2,500 pg/ $\mathrm{ml}, \mathrm{n}=24)$; laboratory reference range, $8-74 \mathrm{pg} / \mathrm{ml}$. Mean ( \pm SD) of follow-up calcium levels after surgery was $8.57 \pm$ $1.02 \mathrm{mg} / \mathrm{dl}$ (range, $5.8-10.3 \mathrm{mg} / \mathrm{dl}, \mathrm{n}=25$ ). Table 1 provides a list of the ultrasound equipment and the frequencies of the high-resolution probes used for parathyroid ultrasound examinations in our centre; Table 2 summarises the patient characteristics.

Parathyroid lesion characteristics

Of the 26 parathyroid lesions with atypical ultrasound findings, $21(80.7 \%)$ were parathyroid adenomas, 2 (7.7\%) were parathyroid adenomas with cellular atypia and $3(11.5 \%)$ were parathyroid carcinomas. Mean length $( \pm \mathrm{SD})$ and weight of the lesion were $32.35( \pm 12.4) \mathrm{mm}$ and $697 \mathrm{mg}$ (range, 50$2500 \mathrm{mg}$ ), respectively. There was no significant difference in
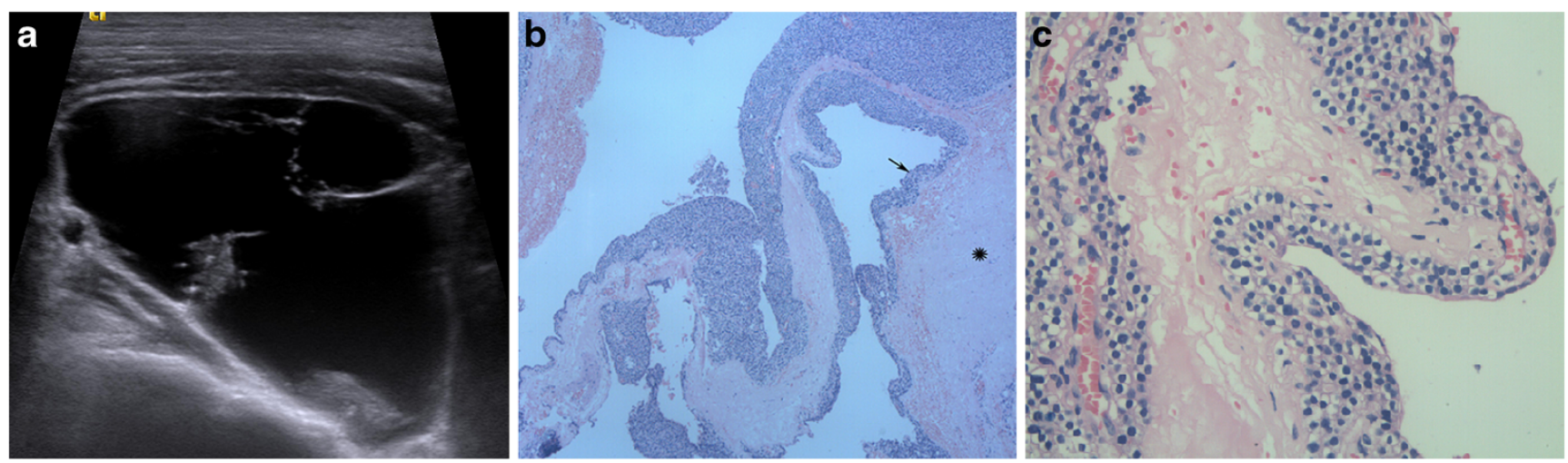

Fig. 1 a Neck ultrasonography of 48-year-old male patient with primary hyperthyroidism showed a predominantly cystic right inferior parathyroid lesion with internal septations. b, c Low-power $(\times 50, \mathrm{H} \& \mathrm{E}$ stain $)$ and high-power $(\times 400, \mathrm{H} \& \mathrm{E}$ stain $)$ photomicrographs of the excised parathyroid lesion show a cystic tumour $(*)$ with cells arranged in nests and an acinar pattern along the wall (arrow) with delicate fibrovascular septa lined by polygonal cells in keeping with cystic parathyroid adenoma 
Fig. 2 a Neck ultrasonography of a 21-year-old female patient with primary hyperthyroidism showed haemorrhagic and cystic degeneration in the right superior parathyroid adenoma. b Lowpower photomicrograph $(\times 50$, H\&E stain) shows an encapsulated tumour composed of lobules of polygonal cells in keeping with parathyroid adenoma with interspersed thinwalled congested blood vessels (short arrows), areas of haemorrhage $(*)$ and cystic degeneration
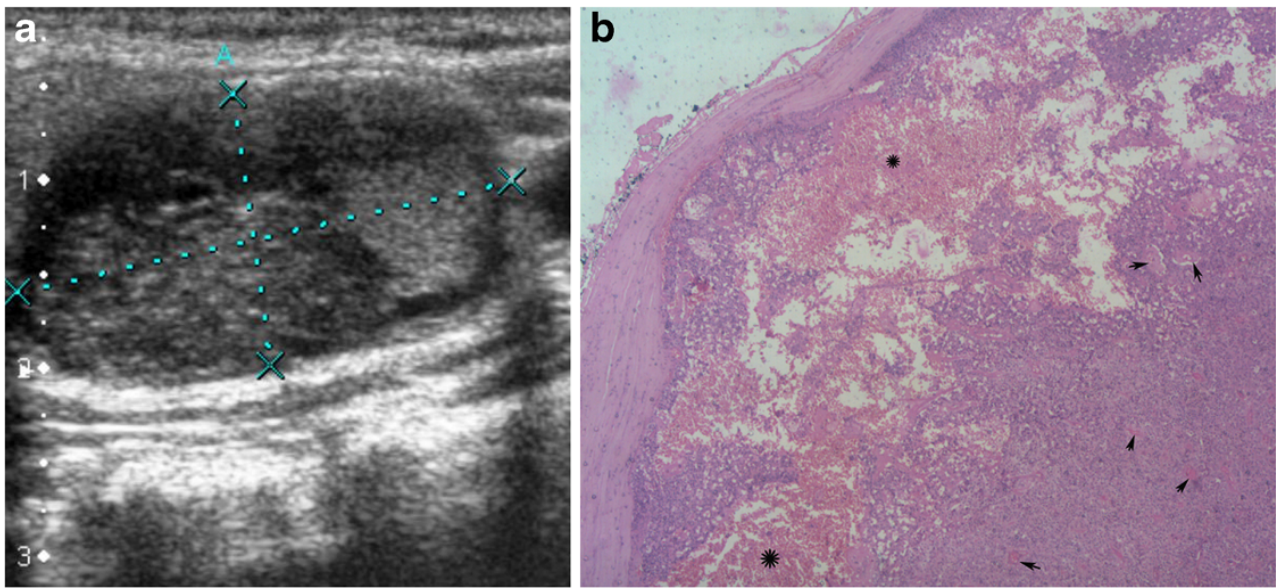

the mean length $(\mathrm{p}=0.071)$ and weight $(\mathrm{p}=0.815)$ of adenomas and carcinomas. Though preoperative mean $( \pm \mathrm{SD})$ serum calcium levels were slightly higher in patients with parathyroid carcinoma $(14.1 \pm 0.64 \mathrm{mg} / \mathrm{dl})$ compared to adenoma $(12.1 \pm 0.93 \mathrm{mg} / \mathrm{dl}), \mathrm{p}=0.007$, there was no difference in the levels of parathyroid hormone, $\mathrm{p}=0.239$.

Ultrasound features and correlation with histopathology and clinical presentation

There were equal numbers of lesions on the left and right. Sixteen $(61.5 \%)$ were inferior parathyroid lesions and ten $(39.5 \%)$ were superior. Six $(23.1 \%)$ lesions were round; 15 $(57.7 \%)$ were oval and $5(19.2 \%)$ were elongated. Of the 26 lesions with atypical ultrasound features, 17 (65.4\%) showed cystic changes; 6 (23.1\%) lesions were isoechoic; 1 (3.8\%) lesion was hyperechoic; 1 (3.8\%) lesion had mixed echogenecity with hypoechoic and hyperechoic components; $20(83.3 \%)$ lesions had heterogeneous echotexture, and calcification was seen in $4(15.3 \%)$ lesions.

There was no association between the shape of the lesion, echotexture, echogenicity and cystic changes within the lesions. There was no association between the shape of the lesion and the histopathological type of the parathyroid lesion (chi-square $=2.487, \mathrm{p}=0.288$ ).

Lesions with cystic change

Out of 17 lesions with cystic change, there were 7 superior, 10 inferior; 9 right and 8 left lesions. The degree of cystic change was less than $10 \%$ in six (35.3\%), $10-50 \%$ in six (35.2\%); $50-75 \%$ in three $(17.6 \%)$ and greater than $75 \%$ in two $(11.8 \%)$ lesions.

There was a significant positive correlation between the presence of cystic degeneration and serum PTH level $(\mathrm{r}=$ $0.422, p=0.04)$. However, there was no significant correlation between the duration of disease and the presence of cystic degeneration $(p=0.493)$. There was a significant positive correlation between presence of cystic degeneration and length of the lesion $(\mathrm{r}=0.416, \mathrm{p}=0.035)$.

Lesions with greater than $50 \%$ cystic change were labelled as cystic parathyroid lesions. There were five (19.2 \%) cystic parathyroid lesions and all were adenomas, three were from the superior parathyroid gland and two were from inferior parathyroid gland. Four (19.2\%) of the cystic adenomas were anechoic on ultrasound and showed predominant cystic

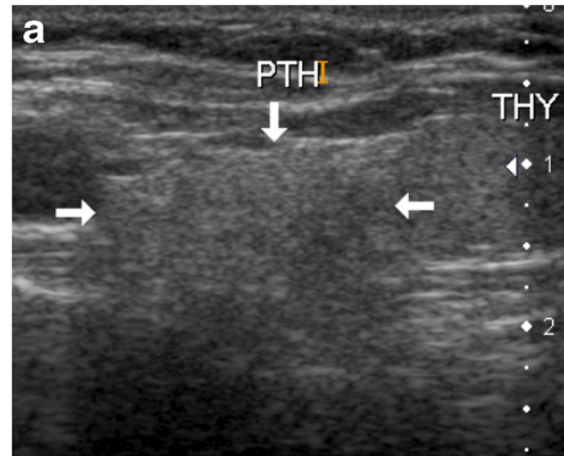

Fig. 3 a Neck ultrasonography of a 62-year-old female patient showed an isoechoic left superior parathyroid lesion. Note that it is difficult to perceive an echogenic rim around the lesion. b Low-power

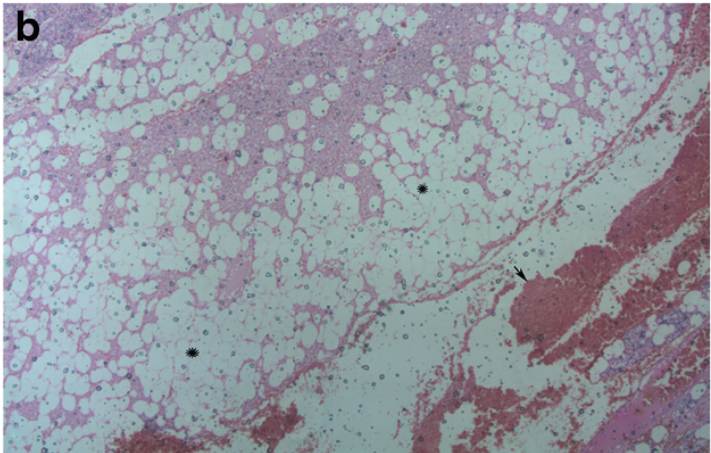

photomicrograph $(\times 50, \mathrm{H} \& \mathrm{E}$ stain $)$ shows a parathyroid adenoma composed of nests of polyhedral cells with extensive fat deposition $\left(^{*}\right)$ and cystic haemorrhagic degeneration (short arrow) 

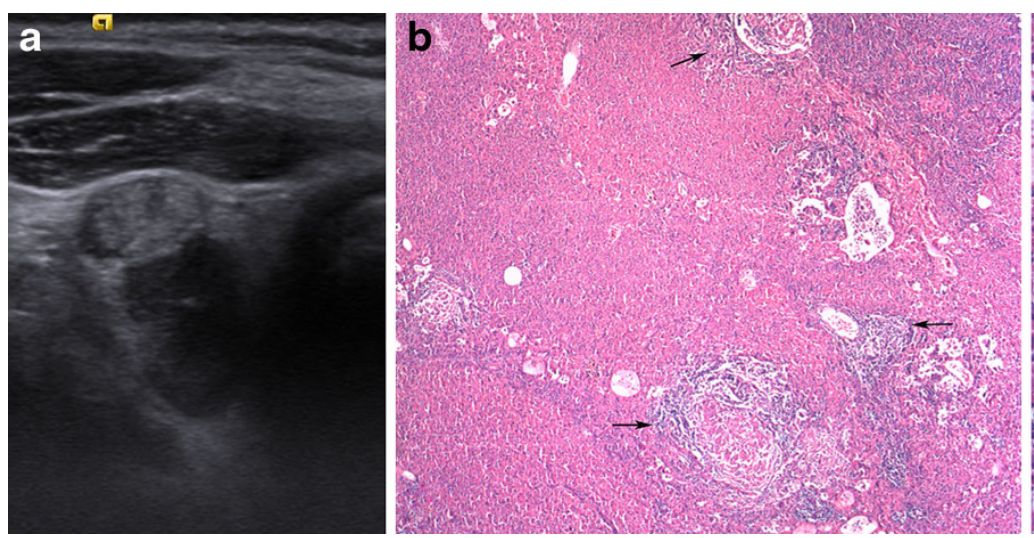

Fig. 4 a Neck ultrasonography of a 55-year-old male patient showed a right inferior parathyroid lesion with hypoechoic and hyperechoic components. b Low-power photomicrograph $(\times 50, H \& E$ stain $)$ shows a section of parathyroid adenoma with multiple discrete granulomas within

change and acinar dilatation on histology (Fig. 1). One cystic lesion had fine cobweb-like internal septations and internal echoes and was a parathyroid adenoma with haemorrhagic and cystic degeneration on histology (Fig. 2).

Cystic parathyroid adenomas were equally distributed among both genders (chi-square $=0.891, \mathrm{p}=0.345$ ). There was significant negative correlation between the cystic parathyroid adenomas and weight of the lesion $(\mathrm{r}=-0.492, \mathrm{p}=$ $0.038)$. The length $(p=0.606)$ and weight $(p=0.209)$ of cystic parathyroid adenomas did not differ from those of other parathyroid adenomas.

Iso- or hyperechogenicity

Five isoechoic lesions and one hyperechoic lesion were all adenomas and showed evidence of haemorrhage, hyalinisation and fibrosis on histology. One isoechoic lesion was an adenoma and had extensive fat deposition on histology (arrows). c High-power photomicrograph $(\times 200$, H\&E stain $)$ shows a well-circumscribed epithelioid granuloma surrounded by lymphocytes amidst oncocytic cells of the parathyroid adenoma

(Fig. 3). One (3.8 \%) lesion, which had both hypoechoic and hyperechoic components, showed evidence of granulomas interspersed between oncocytic cells in a right inferior parathyroid adenoma (Fig. 4). There were no significant neck nodes or evidence of pulmonary tuberculosis in this patient. There was no association between the perception of an echogenic rim/capsule around the lesion and echogenicity (chi-square $=1.426, \mathrm{p}=0.231$ ).

\section{Heterogeneous echotexture}

Two parathyroid carcinomas (Fig. 5), 2 adenomas with cellular atypia and 16 parathyroid adenomas (Fig. 6) were heterogeneous in appearance. Lesions with heterogeneous echotexture on ultrasound showed combinations of acinar dilatation, necrosis, haemorrhage and fibrosis on histology. One of them also showed fat deposition.

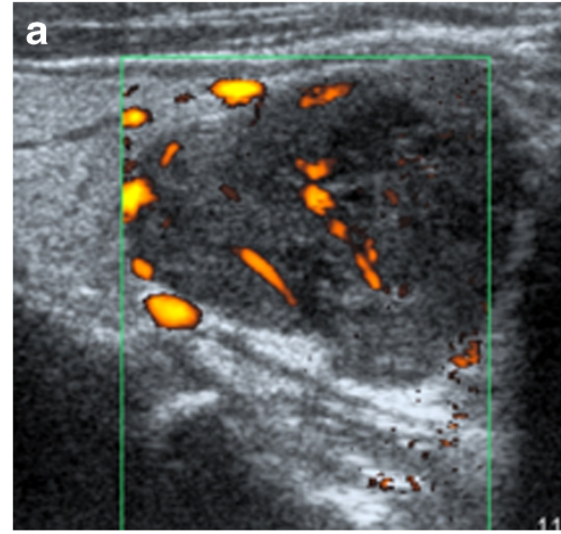

Fig. 5 a Neck ultrasonography of a 42-year-old male patient with parathyroid carcinoma showed a heterogeneous, more rounded left inferior parathyroid lesion with areas of cystic degeneration and ill-defined microlobulated margins. b Low-power photomicrograph $(\times 50, \mathrm{H} \& \mathrm{E}$

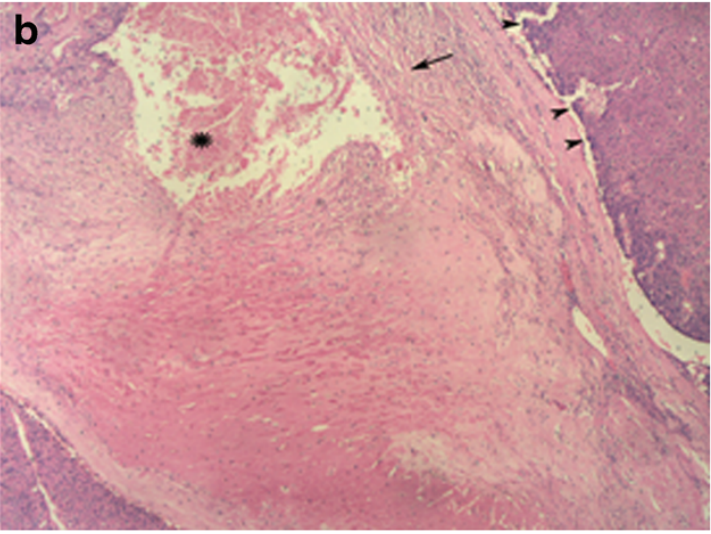

stain) shows a section of parathyroid carcinoma composed predominantly of chief cells of parathyroid with moderate pleomorphism (arrowheads), areas of haemorrhage $(*)$, broad fibrous bands (arrow), capsular and vascular invasion 

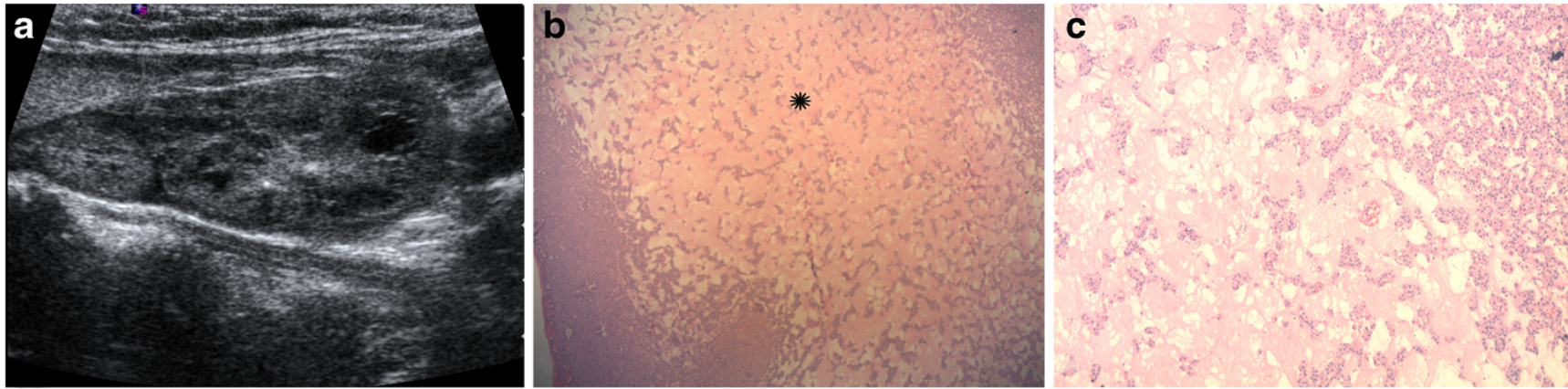

Fig. 6 a Neck ultrasonography of a 60-year-old female patient with parathyroid adenoma showed a heterogeneous, well-defined left inferior parathyroid lesion with areas of cystic degeneration and a speck of

Echogenic rim around the lesion could be seen in $19(76 \%)$ and could not be seen in 6 (24\%). There was no association between the perception of an echogenic rim/capsule around the lesion and echotexture (chi-square $=3.070, \mathrm{p}=0.381$ ).

There was a significant difference between the weight of homogeneous $(225 \pm 35 \mathrm{mg})$ and heterogeneous $(802.7 \pm$ $553.4 \mathrm{mg}$ ) lesions, $\mathrm{p}=0.001$, with a tendency for larger lesions to be heterogeneous in echotexture. There was significant positive correlation between the heterogeneous echotexture and serum PTH level $(r=0.450, p=0.036)$, length of the lesion $(\mathrm{r}=0.566, \mathrm{p}=0.004)$ and weight of the lesion $(\mathrm{r}=0.488, \mathrm{p}=$ $0.047)$. There was no correlation between the duration of disease and echotexture of the lesion $(\mathrm{p}=0.581)$.

\section{Calcification (Fig. 7)}

Of the four lesions with calcification, three were parathyroid adenomas and one was a parathyroid carcinoma. Presence of calcification did not affect the visibility of the echogenic capsule, chi-square $=1.077, \mathrm{p}=0.299$.

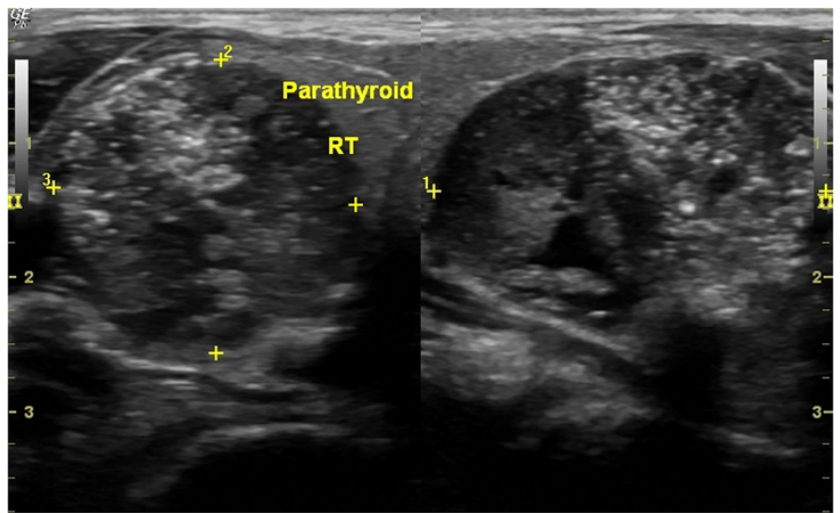

Fig. 7 Neck ultrasonography showed a calcified right inferior parathyroid adenoma in a 27-year-old male patient with primary hyperparathyroidism. An echogenic rim around the lesion could be seen inspite of calcification calcification. b, c Low-power photomicrographs $(\times 25$ and $\times 100$, H\&E stain) showing adenoma with cystic and haemorrhagic degeneration $(*)$

Performance of Tc-99m sestamibi scintigraphy

Tc-99m sestamibi scintigraphy was concordant in 22 $(95.7 \%), n=23$. Scintigraphy was discordant in one patient (4.3\%) who had double adenoma in both the inferior parathyroid glands. The left inferior cystic parathyroid adenoma, which measured $10 \times 4 \mathrm{~mm}$ and weighed $50 \mathrm{mg}$, was not seen on Tc-99m sestamibi scintigraphy (Fig. 8). This lesion was one of two lesions with $>75 \%$ cystic change. Histopathology showed acinar dilatation and haemorrhage in this lesion (Fig. 8).

\section{Surgery and outcome}

Fifteen $(57.7 \%)$ patients had focussed parathyroid surgery and $11(43.2 \%)$ had cervical exploration. All the operations in this group were successful in curing hyperparathyroidism. There was no record of rupture during surgery for the cystic lesions. Eleven patients developed hypocalcaemia. Nine required correction with intravenous calcium and the rest had transient hypocalcaemia. Of the nine patients with symptomatic hypocalcaemia, eight had large parathyroid lesions with cystic degeneration with lengths ranging from 3.5 to $6 \mathrm{~cm}$. There was a significant association between postoperative symptomatic hypocalcaemia and presence of cystic degeneration $(\mathrm{p}=0.004)$.

\section{Discussion}

In our series approximately $10 \%$ of patients who underwent ultrasound for primary hyperparathyroidism had atypical ultrasound features in parathyroid lesions. Parathyroid carcinomas constituted $11.5 \%$ of lesions with atypical ultrasound findings in our series while they constitute $<1 \%$ of all parathyroid lesions detected on ultrasound [1]. A retrospective view of our data revealed that of the 264 parathyroid lesions, $8(3 \%)$ were parathyroid carcinomas. Though the numbers are 
Fig. 8 a, b Neck

ultrasonography of a 31-year-old female patient with primary hyperparathyroidism shows evidence of double adenoma involving the right and left inferior parathyroid glands. The left inferior parathyroid lesion was predominantly cystic. c, d Tc-99m sestamibi scintigraphy and SPECT revealed only the right inferior parathyroid adenoma and the left inferior lesion seen on ultrasonography was not seen. e High-power photomicrograph $(\times 100, \mathrm{H} \& \mathrm{E}$ stain) of the left inferior parathyroid lesion, which was negative on scintigraphy and SPECT, shows acinar dilatation (arrowheads) and haemorrhage
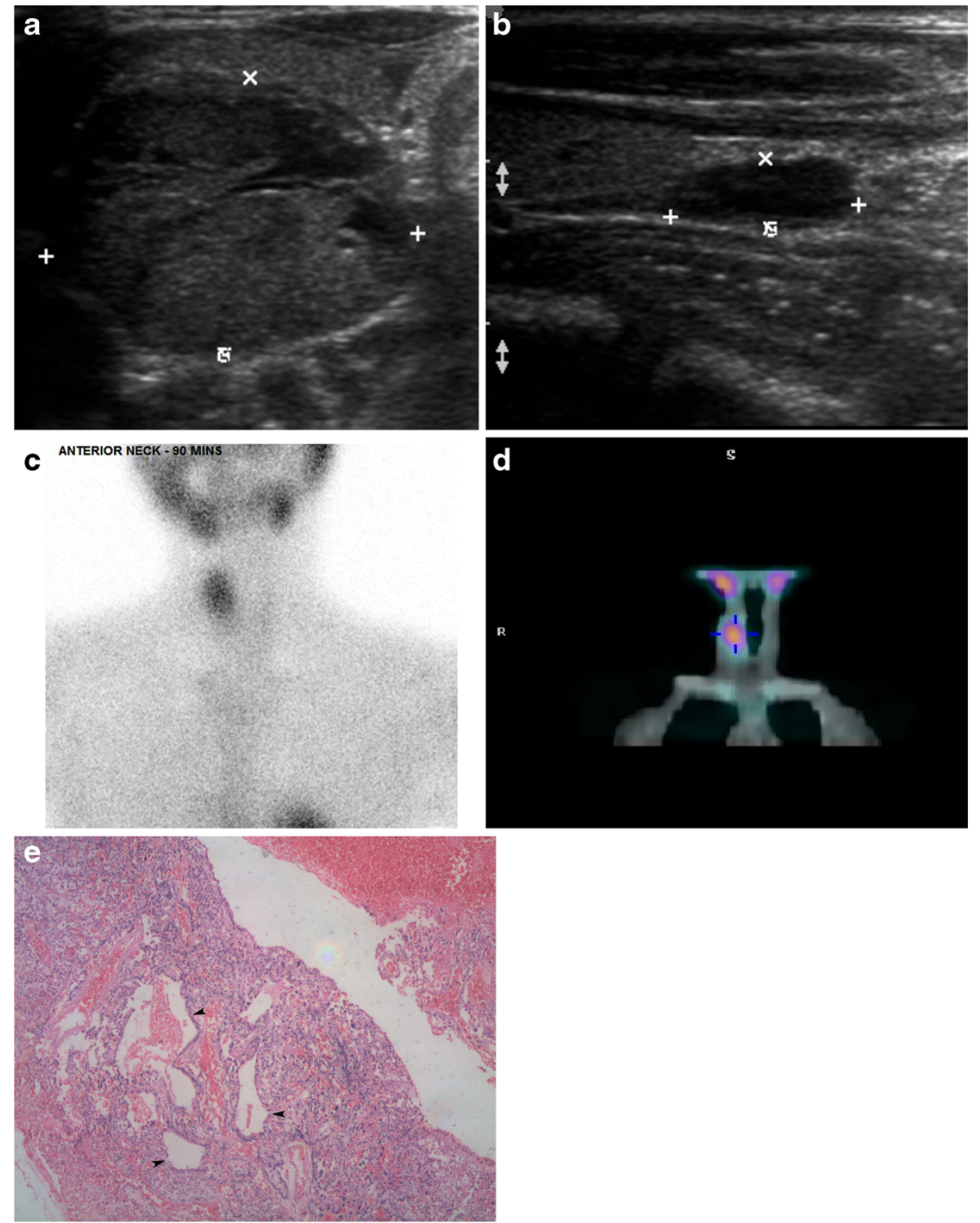

small, the prevalence of parathyroid carcinoma among lesions with atypical ultrasound features seems to be higher $(11.5 \%)$ than among lesions with typical ultrasound features $(1.8 \%)$. Heterogeneous echotexture, cystic change and calcification were the atypical ultrasound features seen in parathyroid lesions. Usually parathyroid lesions are well defined, homogeneous, hypoechoic and oval in shape. The homogeneous appearance is due to the homogeneous arrangement of chief cells within the lesion and the oval shape is due to growth along the longitudinally oriented tissue plane [7]. There were 20 lesions in our series with a heterogeneous appearance. Heterogeneous echotexture is due to the heterogeneous histological appearance caused by fibrosis, haemorrhage, cystic change and fat deposition [9]. In our series, haemorrhage, acinar dilatation and fibrosis were commonly seen in these lesions; however, fat deposition was seen in only one lesion. Similarly, isoechoic and hyperechoic parathyroid lesions also showed evidence of haemorrhage, hyalinisation and fibrosis.

One lesion with both hyperechoic and hypoechoic components showed evidence of granulomatous inflammation suspicious for tuberculosis. This patient did not have any other focus of tuberculosis. Tuberculosis of the parathyroid gland is extremely rare and the literature on this entity is limited to a few case reports $[10,11]$. To the best of our knowledge, there is no literature in the English language on the ultrasound appearance of tuberculosis of the parathyroid gland. 
Pathology studies show calcification is a rare finding in parathyroid lesions and is seen in only $5 \%$ of lesions, predominantly in the capsule [8]. There were four parathyroid lesions with calcification detected on ultrasonography in our series; none were capsular in location. Calcification is reportedly more common in parathyroid carcinomas than in adenomas [12] and one of the four lesions with calcification was a parathyroid carcinoma in our series. Calcification is a common finding in thyroid lesions and often a useful finding that helps differentiate a thyroid from a parathyroid lesion $[8,13]$. However, rarely there can be metaplastic calcification in parathyroid lesions. In these lesions, taking note of the echogenic rim around the lesion would help differentiate it from a thyroid nodule. An echogenic rim was seen in all four parathyroid lesions with calcification.

Among patients undergoing parathyroidectomy, the incidence of cystic change in parathyroid lesions was more common (6.4\%) in our setting compared to that described in the literature, which ranged from $3-4 \%[7,14]$. All the cystic lesions described in our series were functional parathyroid lesions. A male predominance and predilection for left inferior parathyroid lesions described in the literature among patients with functional parathyroid cysts was not seen in our series [14-17]. Histologically all cystic lesions in our series were adenomas with cystic degeneration. There were no pure parathyroid cysts with epithelial lining. The cystic change appears to be a finding seen in larger lesions and was not related to the duration of illness. Larger lesions have more tendencies to undergo haemorrhage and cystic degeneration - the cause of cystic change - perhaps because these large lesions outgrow their vascular supply. The higher incidence of cystic change seen in our series may be related to the larger lesions in our patients. There were no patients with multiple cystic lesions in our series. Tc-99m sestamibi scintigraphy and SPECT are frequently non-diagnostic in cystic parathyroid lesions, with previous studies showing 30-68 \% accuracy [6, 14]. However the accuracy of preoperative localisation improved to $79 \%$ when Tc-99m sestamibi SPECT was interpreted along with ultrasound findings [6]. In our series only one cystic parathyroid lesion was not localised on Tc-99m sestamibi scintigraphy and SPECT.

Typical ultrasound features such as an echogenic rim around the lesion and feeding artery sign are also seen in parathyroid lesions with cystic change and will aid in correctly identifying parathyroid lesions inspite of the cystic change [6]. These features must be used to localise the lesion. Aspiration of the fluid and parathyroid hormone assay may be performed on equivocal lesions when the diagnosis is in doubt $[6,14,16$, 17]. Patients with large cystic parathyroid lesions are known to develop postoperative symptomatic hypocalcaemia [14]; a similar phenomenon was observed in $47 \%$ of patients with cystic parathyroid lesions in our series.

Limitations of the study include its retrospective nature and the small number of subjects studied. However this could not be avoided considering the rarity of these findings.
In conclusion, awareness of atypical ultrasound features of parathyroid lesions will help improve the diagnostic accuracy of ultrasound in detecting parathyroid lesions in patients with hyperparathyroidism. Parathyroid lesions with atypical imaging features are associated with a higher incidence of malignancy. Larger lesions have a greater trend to undergo cystic degeneration. Radiological signs such as an echogenic rim around the lesion and feeding artery sign are also useful in correctly characterising parathyroid lesions with atypical imaging features and should be looked for while attempting to characterise neck lesions in cases of primary hyperparathyroidism.

Open Access This article is distributed under the terms of the Creative Commons Attribution License which permits any use, distribution, and reproduction in any medium, provided the original author(s) and the source are credited.

\section{References}

1. Ruda JM, Hollenbeak CS, Stack BC Jr (2005) A systematic review of the diagnosis and treatment of primary hyperparathyroidism from 1995 to 2003. Otolaryngol Head Neck Surg 132(3):359-72

2. Casara D, Rubello D, Pelizzo MR, Shapiro B (2001) Clinical role of $99 \mathrm{mTcO} 4 / \mathrm{MIBI}$ scan, ultrasound and intra-operative gamma probe in the performance of unilateral and minimally invasive surgery in primary hyperparathyroidism. Eur $\mathrm{J}$ Nucl Med 28(9):1351-9

3. Johnson NA, Tublin ME, Ogilvie JB (2007) Parathyroid imaging: technique and role in the preoperative evaluation of primary hyperparathyroidism. AJR Am J Roentgenol 188(6):1706-15

4. Reeder SB, Desser TS, Weigel RJ, Jeffrey RB (2002) Sonography in primary hyperparathyroidism: review with emphasis on scanning technique. J Ultrasound Med 21(5):539-52, quiz 53-4

5. Lane MJ, Desser TS, Weigel RJ, Jeffrey RB Jr (1998) Use of color and power Doppler sonography to identify feeding arteries associated with parathyroid adenomas. AJR Am J Roentgenol 171(3):819-23

6. Johnson NA, Yip L, Tublin ME (2010) Cystic parathyroid adenoma: sonographic features and correlation with 99mTc-sestamibi SPECT findings. AJR Am J Roentgenol 195(6):1385-90

7. Randel SB, Gooding GA, Clark OH, Stein RM, Winkler B (1987) Parathyroid variants: US evaluation. Radiology 165(1):191-4

8. Polga JP, Balikian JP (1971) Partially calcified functioning parathyroid adenoma. Case demonstrated roentgenographically. Radiology 99(1):55-6

9. Rastad J, Fransson A, Lindgren PG, Johansson H, Ljunghall S, Malmaeus J et al (1984) Ultrasonic appearance of adenomatous and hyperplastic parathyroid glands. Acta Radiol Diagn (Stockh) 25(6): $471-5$

10. Jacob PM, Sukumar GC, Nair A, Thomas S (2005) Parathyroid adenoma with necrotizing granulomatous inflammation presenting as primary hyperparathyroidism. Endocr Pathol 16(2):157-60

11. Kar DK, Agarwal G, Mehta B, Agarwal J, Gupta RK, Dhole TN et al (2001) Tuberculous granulomatous inflammation associated with adenoma of parathyroid gland manifesting as primary hyperparathyroidism. Endocr Pathol 12(3):355-9

12. Lineaweaver W, Clore F, Mancuso A, Hill S, Rumley T (1984) Calcified parathyroid glands detected by computed tomography. J Comput Assist Tomogr 8(5):975-7 
13. Seltzer SE, Balikian JP, Birnholz JC, Hargreaves H, Cartier P, Herman PG (1978) Giant hyperplastic parathyroid gland in the mediastinum-partially cystic and calcified. Radiology 127(1): 43-4

14. McCoy KL, Yim JH, Zuckerbraun BS, Ogilvie JB, Peel RL, Carty SE (2009) Cystic parathyroid lesions: functional and nonfunctional parathyroid cysts. Arch Surg 144(1):52-6, discussion 6
15. Clark OH (1978) Hyperparathyroidism due to primary cystic parathyroid hyperplasia. Arch Surg 113(6):748-50

16. Clark OH (1978) Parathyroid cysts. Am J Surg 135(3):395402

17. Lack EE, Clark MA, Buck DR, King DR (1978) Cysts of the parathyroid gland: report of two cases and review of the literature. Am Surg 44(6):376-81 